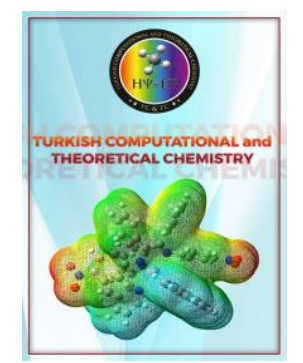

Received: 29.08 .2018
Turkish Computational and Theoretical Chemistry

Turkish Comp Theo Chem (TC\&TC)

Volume(Issue): 3(1) - Year: 2019 - Pages: 1-4

e-ISSN: 2602-3237

https://doi.org/10.33435/tcandtc.455731

Accepted: 25.10 .2018

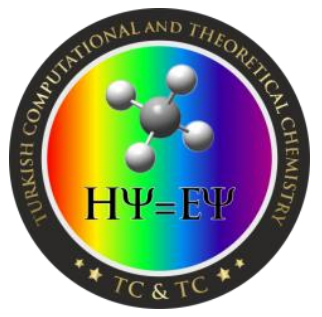

Research Article

\title{
A Theoretical Investigation of TNT in Different Phases
}

\section{by Using DFT}

\section{Faik GÖKALP ${ }^{l}$}

Department of Mathematic and Science Education, Faculty of Education, Kırıkkale University, 71450, Kırıkkale, Turkey

\begin{abstract}
Trinitrotoluene (TNT) is an important aromatic organic based explosives. The computational analysis of the effect of phases (ethanol, methanol, and water) is essential to determine the sensitivity of it. In this study; I investigate the stability, the reactivity of TNT in different phases by using density functional theory (DFT). The results suggest optimization approaches for TNT based on DFT methods B3LYP functional and 6-31G containing polarizing functions $(\mathrm{d}, \mathrm{p})$ basis set for these explosives by selecting the sensitive phase of the explosive analyte.
\end{abstract}

Keywords: TNT, DFT, methanol, ethanol, water

\section{Introduction}

TNT was being synthesized in 1863 by Wilbrad [1]. TNT is an aromatic organic based explosive [2]. The computational temperature analysis on the effect of temperature to TNT correlates closely with the experimental results [3]. The solubility of TNT at room temperature is very low, but it is well soluble in solvents such as ethanol, acetone, and methanol. TNT is a stable, non-hydrating compound as it has low water solubility and is not sensitive to stimulants such as friction, shock and electrostatic energy [4,5]. The physicochemical properties of TNT lead to the transport of active compounds from ground to groundwater. Low water solubility and water absorption properties make it easy to use in damp environments [6]. The manufacturing, usage, and disposal of TNT for military activities have caused contamination of both soil and groundwater. Although TNT is widely used as an explosive material, there are toxic effects of TNT on many organisms including humans and because of the symmetrical arrangement of the nitro

\footnotetext{
${ }^{1}$ Corresponding Author

e-mail: akgokalp@gmail.com
}

groups in the structure of TNT, it can stay in nature without degradation for a long time [7]. TNT is an important poisonous material and it injures many cells, tissues, and organs such as liver, bone marrow, and kidney. Acute yellow atrophy of the liver, aplasia of the bone marrow, petechial hemorrhages, and toxic nephritis is the mainly pathologic findings [8]. Türker and Varıs computationally indicated that the poisoning effect of TNT occurred on the sex life via female sex hormone estrone. TNT may interfere with the hormonal system and neurotransmission processes [9] and activities upon interaction with epinephrine [10]. Folic acid (FA) is known to take place in synthesis, renovation, and methylation of DNA, as well as a cofactor in certain biological reactions to the strong interactions between TNT and FA, may affect as FA related biological activities [11]. In our study; We have investigated the stability of TNT in different phases (ethanol, methanol) by using DFT. 


\section{Faik GÖKALP}

\section{Method}

In this study, the stability calculations of TNT were done in the ethanol, methanol and water phases. The dielectric constants of ethanol, methanol, and water were determined as 24.55 , 32.63 and 78.39 respectively [12]. DFT procedure was used as the calculation method. DFT methods B3LYP functional and 6-31G containing polarizing functions $(d, p)$ basis set was used. Geometry optimization of TNT was performed in ethanol, methanol and by using the mentioned functional and basis set. HOMO and LUMO energy levels and dipole moment values were obtained after optimization procedure [13].

\section{Results and discussion}

HOMO, LUMO, $\Delta$ (HOMO-LUMO) and Dipole Moment values of TNT are given in Table 1. The molecular structure of TNT is given Fig. 1.

Table 1. HOMO, LUMO, $\Delta$ (HOMO-LUMO) and Dipole Moment values of TNT

\begin{tabular}{lccc}
\hline DFT & TNT in ethanol & TNT in methanol & TNT in water \\
\hline Dipol moment (Debye) & 3.5566 & 3.5704 & 3.5948 \\
HOMO (eV) & -0.30170 & -0.30150 & -0.30112 \\
LUMO (eV) & -0.12941 & -0.12929 & -0.12265 \\
(HOMO-LUMO) (eV) & -0.17229 & -0.17221 & -0.17847 \\
\hline
\end{tabular}

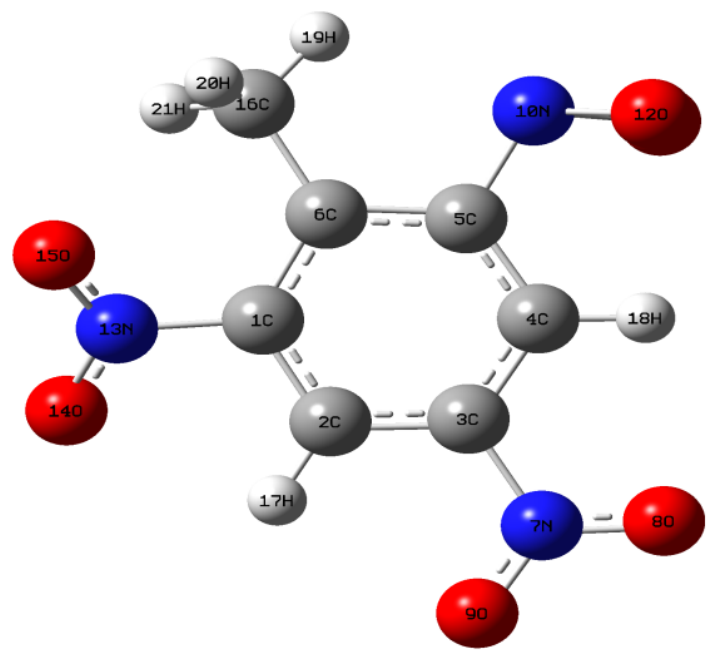

Fig. 1. The molecular structure of TNT

Nilesh and et al. indicated that a molecule having a small frontier orbital gap is more polarizable and usually associated with a high chemical reactivity, low kinetic stability, and termed as soft molecule [14].

According to data from Table 1; Stability; (HOMO-LUMO difference) is from large to small;

TNT in water > TNT in ethanol > TNT in methanol

Polarity: (Dipole moment)

TNT in water $>$ TNT in methanol $>$ TNT in ethanol
TNT in water has a large frontier orbital gap so 1t has low chemical reactivity and high kinetic stability. Our theoretical results show that the stability of TNT in water is higher than the others. Moreover, TNT in methanol is more unstable than the others. So, it can interact with other molecules more easily.

The first explosives are the crucial importance components in detonators and primers, used for initiating the elements to many military items such as small, medium, and large caliber munitions, mortars, artillery, and warheads [15]. TNT can be strongly adsorbed in the carbon nanotube exterior 
surface [16]. Molecules having high HOMO energy can donate their electrons more easily compared to molecules with low HOMO energy, and so they are more reactive in oxidation reactions. On the other hand, molecules having low LUMO energy are more convenient to accept electrons than molecules with high LUMO energy [10].

In literature 4, 5 mentioned above; TNT is a stable, non-hydrating compound as it has low water solubility and is not sensitive to stimulants such as friction, shock, and electrostatic energy.

There is very good agreement between calculated isotopic shifts of nitrobenzene and those observed experimentally by using DFT [17]. Cooper emphasized that the best arrangement between experimentally identified absorption energies and those calculated by TD-DFT with the smallest basis set of $6-31+\mathrm{G}(\mathrm{d})$ [18]. "The lp...П interaction competes successfully with the N-H... $\Pi$ and $\mathrm{N}-\mathrm{O} . . . \mathrm{H}$ hydrogen bonds but are weaker than the conventional C-H...N hydrogen bond. The results also indicate that the competition between hydrogen bonding and $1 \mathrm{p} . . . \Pi$ interaction in TNT" [19]. The sensitivity of explosives is related with the HOMO-LUMO energy gap. If it has narrowed the gap of the explosive is more sensitive [20]. Explosive encapsulated microspheres were important techniques for trace explosive detection because of their precise size, shape, and composition [21] so the stability of them would be investigated in different phases by using the Gaussian 09W [22]. In this study; the HOMOLUMO energy gap of TNT in ethanol narrow and not stable. So, it is more sensitive to explode.

\section{Conclusion}

The presented results indicate that the stability of TNT in water is more than the others. Moreover, TNT in methanol is more unstable than the others. So, it can form the complex with the other functional groups. The HOMO-LUMO energy gap of TNT in methanol narrow So it is more sensitive to explode.

\section{Conflicts of interest}

There are no conflicts to declare.

\section{Acknowledgments}

This study is supported by the Scientific Research Projects of Kirıkkale University (BAP2016/016,2017/019).

\section{References}

[1] G. C. Smith, TNT, 1918, pp. 17-18, New York.

[2] L. Türker, S. Variş, A Review Of Polycyclic Aromatic Energetic Materials, Polycyclic Aromatic Compounds 29 (2009) 228-266.

[3] R. Cohen, Y. Zeiri, E. Wurzbuerg, R. Kosloff, J. Phys. Chem. 111(43) (2007) 1107-11083.

[4] H. A. Mercimek, Microbial bio degradation of 2,4,6-trinitrotoluene. Cukurova University, Doctorate Thesis, (2011) 158p, Adana.

[5] A. Üzer, Basic and Derivative Spectrophotometric Analysis of Some Nitrophenols. Istanbul University, Master Thesis, (2004) 77p, Istanbul.

[6] G. Özcan, F. İ. Türkdoğan, Bioremediation Techniques for Elimination of Pollution in Military Areas, KSU Engineering Science Review, 17 (1) (2014).

[7] Z. G. Gök, M. İnal, M. Yiğitoğlu, Microbial Degradation of 2, 4, 6-Trinitrotoluene (TNT) and Bioremediation of Polluted Areas by TNT, European Journal of Science and Technology 4-7 (2016) 38-50.

[8] R. H. Dreisbach, Handbook of Poisoning, 7th ed., Lange Medical Publications, Los Altos, CA, USA, p. 127, 1971.

[9] L. Türker, S. Varıs, A Possible Complex between TNT and Epinephrine - A DFT Study, Z. Anorg. Allg. Chem. 640(2) (2014) 334-338.

[10] L. Türker, Ç. Ç. Bayar, A DFT Study on Estrone - TNT Interaction, Z. Anorg. Allg. Chem. 639(10) (2013) 1871-1875

[11] L. Türker, S. Variş, Spectroscopic Studies On A Potential Complex Between Tnt And Folic Acid: A Dft Study, Chemistry: Bulgarian Journal of Science Education 255 (2016).

[12] Z. Varmaghan, M. Monajjemi, F. Mollaamin, Ab Initio Study of VinblastineTubulin Anticancer Complex, Biomacromolecular Journal 1-1 (2015) 4651.

[13] F. Gökalp, A theoritical study of Curcuma longa's anticancer agents, curcumin I and 
curcumin II, in blood and gas by using density functional theory (DFT) and hartree-fock (HF), International Journal of Medicine and Medical Sciences 6 (2014) 146-150.

[14] U. J. Jadhao, A. B. Naik, Effect of electronegativity on structural, spectrophotometric and thermo-chemical properties of fluorine and chlorine substituted isoxazoles by DFT method, Cogent Chemistry 3 (2017) 1296342.

[15] N. Mehta, K. Oyler, G. Cheng, A. Shah, J. Marin, K. Yee, Primary Explosives, Z. Anorg. Allg. Chem. 640(7) (2014) 13091313.

[16] M. Mahkam, J. Aboudi, M. Nouraliei, Determination of carbon nanotubes as sensor identifying TNT,RDX and NQ molecules using DFT method, Extensive Journal of Applied Sciences 3-5 (2015) 169173.

[17] J. Clarkson, W. E. Smith, A DFT analysis of the vibrational spectra of nitrobenzene, Journal of Molecular Structure 655 (2003) 413-422.

[18] J. K. Cooper, C. D. Grant, J. Z. Zhang, Experimental and TD-DFT Study of Optical Absorption of Six Explosive Molecules: RDX, HMX, PETN, TNT, TATP, and HMTD, J. Phys. Chem. A. 117 (2013) 6043-6051.

[19] A. Mei-Zhen, T. Zhi-qiang, L. De-Yin HaiXia, W. Xin, A theoretical investigation of the competition between hydrogen bonding and lone pair interaction in complexes of
TNT with NH3, Computational and Theoretical Chemistry 1064 (2015) 25-34.

[20] L. Türker, Interaction of TNT and Aluminum - A DFT Treatment, Z. Anorg. Allg. Chem. 641(2) (2015) 408-413.

[21] T. Brewer, M. Staymates, R. Fletcher, Quantifying Trace 2,4,6-Trinitrotoluene (TNT) in Polymer Microspheres, Propellants Explos. Pyrotech. 41 (2016) 160 $-165$.

[22] Gaussian 09, Revision A.02, M. J. Frisch, G.W. Trucks, H. B. Schlegel, G. E. Scuseria,M. A. Robb, J. R. Cheeseman, G. Scalmani,V. Barone, B. Mennucci, G. A. Petersson, H.Nakatsuji, M. Caricato, X. Li, H. P.Hratchian, A. F. Izmaylov, J. Bloino, G.Zheng, J. L. Sonnenberg, M. Hada, M.Ehara, K. Toyota, R. Fukuda, J. Hasegawa,M. Ishida, T. Nakajima, Y. Honda, O. Kitao,H. Nakai, T. Vreven, J. A. Montgomery, Jr.,J. E. Peralta, F. Ogliaro, M. Bearpark, J. J.Heyd, E. Brothers, K. N. Kudin, V. N.Staroverov, R. Kobayashi, J. Normand, K.Raghavachari, A. Rendell, J. C. Burant, S. S.Iyengar, J. Tomasi, M. Cossi, N. Rega, J. M.Millam, M. Klene, J. E. Knox, J. B. Cross,V. Bakken, C. Adamo, J. Jaramillo, R.Gomperts, R. E. Stratmann, O. Yazyev, A.J. Austin, R. Cammi, C. Pomelli, J. W.Ochterski, R. L. Martin, K. Morokuma, V.G. Zakrzewski, G. A. Voth, P. Salvador, J.J. Dannenberg, S. Dapprich, A. D. Daniels,Ö. Farkas, J. B. Foresman, J. V. Ortiz, J.Cioslowski, and D. J. Fox, Gaussian, Inc., Wallingford CT, 2009. 